\title{
Atuação do Ministério do Trabalho na fiscalização das condições de segurança e saúde dos trabalhadores, Brasil, 1996-2012
}

\author{
Brazilian Ministry of Labor's inspection on workers' safety and \\ health, Brazil, 1996-2012
}

\begin{abstract}
${ }^{1}$ Ministério do Trabalho e Emprego. Brasília, DF, Brasil.

Contato:

Fernando Donato Vasconcelos

E-mail:

fdvasconcelos@gmail.com

O trabalho não se baseia em tese ou dissertação e não foi apresentado em reunião científica.
\end{abstract}

Trabalho não subvencionado.
Recebido: 10/12/2012

Revisado: 26/06/2013

Aprovado: 22/01/2014

\section{Resumo}

Os acidentes e doenças do trabalho, mesmo com as altas taxas de morte e invalidez no Brasil, ainda são agravos negligenciados. Objetivos: o estudo avalia a atuação do Ministério do Trabalho do Brasil no período 1996-2012, na área de segurança e saúde no trabalho (SST), com ênfase nas ações desenvolvidas em 2011. Métodos: analisa documentos e dados registrados no Sistema Federal de Inspeção do Trabalho relacionados à fiscalização das normas de SST pelos auditores fiscais do trabalho, especialmente as que exigem maior presença no ambiente laboral. Compara áreas de atuação com indicadores relacionados à incapacidade por acidentes e mortalidade no trabalho. Resultados: estimou-se que as ações em SST são executadas por 785 auditores (25,1\% do quadro). Identificaram-se mudanças no perfil das ações de SST, com aumentos das sanções e dos embargos e interdições em razão de risco grave e iminente à saúde e à vida. As ações são, geralmente, pouco abrangentes e não se destinam aos setores com maiores taxas de mortalidade e invalidez resultantes de acidentes do trabalho. Conclusões: o modelo atual dilui excessivamente ações de SST dentro do conjunto das ações de inspeção do trabalho. Não prioriza a fiscalização em áreas que apresentam piores indicadores de morbimortalidade ocupacional e mantém um quadro insuficiente de auditores dedicados prioritariamente à SST. A atuação dos inspetores ocorre sem estrutura material e orçamentária adequadas e, por vezes, sem a formação técnica necessária.

Palavras-chave: saúde do trabalhador; segurança no trabalho; inspeção do trabalho; acidentes do trabalho.

\begin{abstract}
Background: even with high rates of death and disability, occupational injuries and diseases are "neglected health problems" in Brazil. Objective: to study the Brazilian Ministry of Labor's performance concerning occupational safety and health (OSH) in the period 1996-2012, with emphasis to 2011. Methods: documents produced by the Federal System for Labor Inspection related to the labor inspections of OSH standards were analyzed, especially those requiring detailed inspections and longer presence at worksites. The study also compares targeted areas of inspection with higher work-related disability and mortality indicators. Results: OSH actions were taken by 785 inspectors $(25,1 \%$ of the staff). We have identified changes in the OSH inspection profiles with increased number of penalties due to serious and eminent health and life risks. It was found that inspections were not inclusive enough and did not address sectors presenting the highest mortality and disability rates as result of occupational injuries. Conclusion: the present institutional model exceedingly attenuates OHS acting in labor inspection procedures. It does not take into account areas that show the worst occupational morbimortality indicators and keeps a very small staff of auditors fully dedicated to OSH. These inspectors work in a limited material and budgetary infrastructure, and, not rarely, lack proper technical training.
\end{abstract}

Keywords: workers' health; safety at work; labor inspection; occupational injuries. 


\section{Introdução}

Os agravos à saúde do trabalhador no Brasil apresentam grande relevância e desafiam as políticas públicas e a atuação do Estado. Tome-se como exemplo o mais grave desses eventos - a morte resultante do chamado acidente do trabalho.

Embora a taxa de mortalidade específica por acidentes do trabalho (medida pelo número de óbitos devidos a acidentes do trabalho, por 100 mil trabalhadores segurados pela Previdência Social, em determinado espaço geográfico, no ano considerado) venha diminuindo no Brasil há mais de duas décadas, reduzindo de 21,3 por 100 mil trabalhadores segurados, em 1999, para 7,55 por $100 \mathrm{mil}$, no ano de 2009, e 7,35 em 2011, a elevada quantidade de mortes no trabalho ainda representa uma clara indicação de que o país mantém os acidentes e doenças do trabalho entre os chamados "agravos negligenciados", pois, afinal, entre 2002 e 2011 ocorreram em média 2796 (mediana $=2808$ ) mortes evitáveis no trabalho a cada ano, considerado o segmento formal do mercado de trabalho (BRASIL, 2011a; BRASIL, 2012a; BRASIL, 2012b).

Os agravos à saúde negligenciados são aqueles que não só prevalecem em condições de pobreza, como também contribuem para a manutenção do quadro de desigualdade, representando forte entrave ao desenvolvimento (BRASIL, 2010a). Nesse conceito geralmente são incluídas doenças como dengue, tuberculose, esquistossomose e outras que afetam principalmente as populações mais pobres, mas não os acidentes e doenças do trabalho.

Apenas os empregados públicos e privados sob o regime da Consolidação das Leis do Trabalho (CLT), para efeitos previdenciários e trabalhistas, têm seus acidentes obrigatoriamente informados por Comunicação de Acidente do Trabalho (CAT), constituindo a base principal da estatística acidentária da Previdência Social. Somente eles e os chamados "segurados especiais" (produtores, parceiros, meeiros, arrendatários rurais, pescadores artesanais e assemelhados, assim inscritos na Previdência Social) estão cobertos pelo seguro para acidentes do trabalho (conhecido como SAT), que consiste em um percentual que mede o risco da atividade econômica, com base no qual é cobrada uma contribuição para financiar os benefícios previdenciários decorrentes do grau de incidência de incapacidade laborativa (GIIL-RAT), cuja alíquota de contribuição pode ser igual a 1\% se a atividade é de risco mínimo, $2 \%$ se de risco médio ou de $3 \%$ se de risco grave (BRASIL, 2010b).

Mesmo se tratando de taxas que não atingem todos os casos existentes, quando são comparadas, por exemplo, com as taxas de mortalidade por acidentes do trabalho nos Estados Unidos (EUA), país que tem estatísticas mais abrangentes de acidentes fatais do trabalho (UNITED STATES OF AMERICA, 2009), verifica-se o quanto as nossas são elevadas. Em 2009, houve naquele país 4.340 acidentes do trabalho fatais, com uma taxa de 3,3 por 100 mil trabalhadores em tempo integral, enquanto no Brasil, no mesmo ano, ocorreram 2.560 acidentes fatais, resultando na taxa de mortalidade de 7,55 por 100 mil segurados. Muito embora haja diferenças de critério no conceito de acidente do trabalho entre os dois países, esta simples comparação mostra que, ainda que os acidentes sejam subnotificados no Brasil, temos uma taxa de mortalidade de grandes proporções, observando-se que há vários outros países desenvolvidos com taxas bem menores que os EUA, como, por exemplo, o Reino Unido, com taxa de mortalidade de 0,6 acidentes do trabalho por 100 mil trabalhadores, em 2009, entre empregados e autônomos (HEALTH AND SAFETY EXECUTIVE, 2009).

De 1988 a 2011 ocorreram 82.171 mortes no trabalho em nosso país (BRASIL, 2012b), números que expressam fragilidade das ações de proteção e prevenção em segurança e saúde do trabalhador.

Como se sabe, a redução dos agravos e das mortes relacionadas ao trabalho depende de um conjunto de políticas públicas e de arranjos socioeconômicos, mas não há dúvida de que a fiscalização do Estado sobre as empresas tem relevante papel para que ocorram melhorias nas condições e nos processos de trabalho e de produção que resultam em riscos de doenças e acidentes (CARDOSO; LAGE, 2007; PIRES, 2009).

Desde o momento em que o Estado fixou regras de proteção trabalhista, no intuito de controlar excessos da exploração capitalista, surgiram as primeiras medidas de verificação da sua aplicação, como a proteção ao trabalho das crianças ou das mulheres, a melhoria das condições desumanas de higiene e segurança nas fábricas e das jornadas hiperexaustivas. Como destaca Donato (2008), as normas de proteção à criança e às mulheres visavam resguardar o trabalhador futuro e garantir mão de obra abundante e barata.

Em escala internacional, a estruturação da Inspeção do Trabalho como um corpo especial dentro da Administração do Estado para realizar a fiscalização das normas de proteção trabalhista foi discutida pela primeira vez na Conferência de Berlim realizada em 1890 (GONZÁLEZ, 1997).

A fiscalização da execução das normas protetoras começou a ser feita em 1802 no Reino Unido, através de verificações facultativas das condições de trabalho (GONZÁLEZ, 1997). Mas somente em 1833 foram criados na Inglaterra os primeiros serviços regulares de inspeção das condições laborais fabris, o 
que também ocorreu na Prússia vinte anos depois (DONATO, 2008).

No Brasil, a fiscalização do trabalho de menores de idade em ambientes fabris originou a primeira norma de inspeção do trabalho em 1891 - o Decreto 1313 editado por Deodoro da Fonseca. Embora considerado como marco inicial da inspeção do trabalho no país, era uma norma restrita apenas à capital federal, o Rio de Janeiro (BRASIL, 1891).

Em 1919, através dos artigos 387 a 399 do Tratado de Versalhes, pactuado pelos países que venceram a Primeira Guerra Mundial, foi criada a Organização Internacional do Trabalho - OIT. O Tratado considerou, em seu preâmbulo, a existência de "condições de trabalho que implicam, para grande parte das pessoas, a injustiça, a miséria e as privações, o que gera um descontentamento tal que a paz e a harmonia universais são postas em risco" (INTERNATIONAL LABOUR OFFICE, 1923).

Concluiu o Tratado de Versalhes ser urgente melhorar as condições de trabalho através de medidas como a fixação de uma duração máxima da jornada de trabalho, a garantia de um salário que assegurasse condições básicas de existência, a proteção dos trabalhadores contra as enfermidades gerais ou profissionais e os acidentes do trabalho, a proteção das crianças, adolescentes e mulheres, e a liberdade sindical, dentre outras. E com o objetivo de assegurar a aplicação das leis e regulamentos de proteção aos trabalhadores, aprovou como de especial e urgente importância (artigo 427, item 9) a criação de serviços de inspeção pelos Estados-membros (INTERNATIONAL LABOUR OFFICE, 1923).

O Brasil instalou sua Inspeção do Trabalho em caráter nacional em 1931, como parte do Departamento Nacional do Trabalho - DNT e dispondo de três fiscais, conforme o Decreto $\mathrm{n}^{\circ} 19.671 \mathrm{~A}$, de 4 de Fevereiro de 1931 (BRASIL, 1931). No decorrer do Estado Novo, período de expansão do arcabouço normativo trabalhista no país, a inspeção do trabalho se ampliou. O Decreto-Lei $\mathrm{n}^{\circ}$ 6.479, de 9 de maio de 1944, criou as carreiras de engenheiro de segurança do trabalho (8 cargos), médico do trabalho (16 cargos) e inspetor do trabalho (70 cargos) (BRASIL, 1944). Nota-se que, desde a origem, o número de cargos destinados à fiscalização trabalhista geral era bem superior aos cargos dedicados à fiscalização das normas de segurança e saúde no trabalho, além destes últimos serem reservados apenas a médicos e engenheiros.

Em 1947, através da Convenção nº 81, a OIT regulamentou a inspeção do trabalho na indústria e no comércio. O Brasil a incorporou ao ordenamento jurídico nacional em 1957. A ditadura militar instalada em 1964, entretanto, denunciou a convenção ${ }^{\circ}$
81, em 1971, e, somente após o fim da ditadura, em 1987, ela foi novamente ratificada (BRASIL, 1987). Contudo, o Regulamento de Inspeção do Trabalho RIT, primeira norma que sistematizou a atividade de inspeção no país, data de 1965 (BRASIL, 1965), e foi mantida em vigência até 2002, quando foi alterada para a versão atual (BRASIL, 2002a).

A Constituição Federal (BRASIL, 1988) dispõe no Art. 21, XXIV, que é atribuição exclusiva da União "organizar, manter e executar a inspeção do trabalho" e a legislação ordinária federal estabelece o Ministério do Trabalho e Emprego (MTE) como o responsável pelo exercício dessa atribuição. Todavia, a competência constitucional atribuída ao Sistema Único de Saúde (SUS) para "colaborar na proteção do meio ambiente, nele compreendido o do trabalho" (Art. 200, VIII) tem sido compreendida por alguns autores como a possibilidade do SUS, no âmbito federal, estadual e municipal, exercer a inspeção do trabalho nas "ações em saúde do trabalhador e em ambiente de trabalho" (SANTOS; RESCHKE; MONTEIRO, 1996), entendimento recusado pela Advocacia Geral da União (BRASIL, 2012c).

Este estudo busca traçar um perfil da atuação da Inspeção do Trabalho no âmbito do Ministério do Trabalho e Emprego, desenvolvida por seus auditores-fiscais do trabalho no período de 1996 a 2012, enfocando em particular a fiscalização das normas de proteção à "segurança e saúde no trabalho" (SST), expressão que nomina as ações de proteção à saúde do trabalhador no MTE.

\section{Métodos}

Assim como analisar acidentes e doenças do trabalho no Brasil sempre traz à luz questionamentos sobre a incompletude das bases da Previdência Social (CAT e Benefícios), do Sistema Único de Saúde (Sistema de Informações sobre Mortalidade - SIM e Sistema de Informação de Agravos de Notificação - Sinan) e do MTE (Relação Anual de Informações Sociais - Rais), analisar os resultados da Inspeção do Trabalho no Brasil nos remete à incompletude e segmentação da principal base de dados disponível - a do Sfit (2008), sigla do Sistema Federal de Inspeção do Trabalho, programa eletrônico implantado em 1995 (BRASIL, 1995).

Para maior clareza dos procedimentos metodológicos é importante contextualizar que a criação do programa Sfit objetivava registrar as atividades dos agentes da Inspeção da época - fiscais do trabalho, médicos do trabalho e engenheiros de segurança do trabalho. Além do registro das ações fiscais, visava aferir sua produtividade em relação à parte variável, então existente, da sua remuneração. 
A implantação do Sfit precede a fusão daquelas carreiras na de Auditor Fiscal do Trabalho - AFT, realizada através da Medida Provisória ${ }^{0}$ 1.915-1, de 29/7/1999, que após várias reedições foi consolidada na Lei $\mathrm{n}^{\mathrm{0}}$ 10.593/2002 (BRASIL, 2002b). Precede também a incorporação da Secretaria de Segurança e Saúde no Trabalho (SSST) pela Secretaria de Fiscalização do Trabalho (SEFIT) em 1999, que passou a se chamar de Secretaria de Inspeção do Trabalho (SIT) (BRASIL, 1999).

Justamente por ter sido concebida numa instituição que segmentava as atividades da inspeção do trabalho entre ações de Segurança e Saúde no Trabalho (módulo DSST, em alusão à sigla do Departamento de Segurança e Saúde no Trabalho, que reuniu atividades oriundas da antiga SSST) e de Fiscalização Trabalhista (módulo DEFIT, sigla do Departamento de Fiscalização do Trabalho, que reuniu as principais atividades oriundas da antiga SEFIT), o Sfit separa seus dados nas duas áreas.

Os relatórios de inspeção (RI) são registrados no Sfit no mês em que se iniciou a atividade ("RI não concluído") e no mês que se concluiu a ação ("RI de continuação") naquela empresa, cabendo apenas um RI se a ação se encerra no mesmo mês que começou ("RI concluído"). Para análise, interessarão apenas os dados oriundos dos RI de continuação e dos RI concluídos, porque ali se encontram os resultados colhidos na fiscalização.

Ao registrar um RI, o AFT pode constar resultados relativos aos chamados "atributos de Legislação Trabalhista" (LT) e às Normas Regulamentadoras (NR) de SST. Enquanto a ação de SST é considerada como aquela em que se fiscalizou ao menos um item de NR, a ação fiscal de LT envolve ao menos um resultado dos seguintes "atributos": registro do trabalhador (inclusive pessoa com deficiência ou aprendiz); jornada de trabalho; descanso; salários ou qualquer pagamento que deva ser feito ao empregado; FGTS (Fundo de Garantia do Tempo de Serviço) e Contribuição Social; seguro-desemprego; Rais; vale-transporte; trabalho infantil; e outros itens fiscalizados não especificados antes.

Se um AFT realiza uma ação fiscal em que verifica irregularidades no pagamento de salário e observa condições de insalubridade que violam uma ou mais normas regulamentadoras de SST, ao registrar seu relatório de inspeção (RI) no Sfit, a ação aparecerá tanto no módulo DSST quanto no módulo DEFIT. Por isso, embora seja possível comparar as ações fiscais das duas áreas, só é possível identificar o total de ações fiscais da Inspeção ao suprimir dados que estejam replicados em ambos módulos.

O resultado da fiscalização LT poderá ser identificado pelos seguintes códigos: 1 - regular; 2 - regularizado; 3 - irregular; ou 4 - inspeção de irregularidade crônica sujeita a negociação coletiva. Já o resultado da ação de SST poderá ter os códigos: 1 - regular; 2 - regularizado na ação fiscal; 3 - irregular; 4 - notificado; 5 - embargo; 6 - levantamento de embargo; 7 - interdição; 8 - levantamento de interdição. O registro do código 3 sempre implicará no registro do respectivo auto de infração e no caso das ações de SST não é permitido lançar apenas o código 4 (BRASIL, 2008a).

De acordo com dados da SIT, em 2011, as ações consideradas de SST tinham em média seis ementas de NR, ou seja, referiram resultado relativo a seis itens de SST (BRASIL, 2012d).

Para obter informações gerais sobre a inspeção do trabalho, foram analisados dados do Sfit e documentos gerenciais disponíveis na SIT, além de consultas a publicações oficiais no Diário Oficial da União, no grupo de discussão AFTBrasil ${ }^{2}$ e no sítio oficial do MTE, ambos na internet.

Foram analisados dados do Sfit desde 1996, ano em que os RI passaram a ser digitados pelos AFT no programa, sendo possível comparar o conjunto das ações fiscais das duas áreas - SST e LT, particularmente em relação ao total de ações concluídas e ao número de autos de infração lavrados. Os dados referentes a 2012 foram estimados com base na projeção, para os meses de setembro a dezembro, da média dos dados disponíveis de janeiro a agosto de 2012, em razão do fato deste trabalho ter sido elaborado no último quadrimestre daquele ano. Os dados relativos ao "número de trabalhadores alcançados" não foram utilizados como indicadores de eficiência da inspeção do trabalho por ter se identificado expressiva falta de uniformidade no registro de tais dados.

Embora vários itens da área de LT tenham relação direta com as condições de saúde dos trabalhadores, como a duração da jornada, a avaliação da atuação em SST se concentrou nos dados do Sfit de fiscalização de itens de NR, tendo sido escolhido o ano de 2011, o mais recente disponível quando da elaboração deste artigo, para um maior detalhamento da atuação dos AFT em SST.

Das 34 NR vigentes no segundo semestre de 2012, 27 constaram do texto original da Portaria 3214/78. Uma delas era relativa a disposições gerais

${ }^{2}$ AFTBRASIL - Grupo de discussão sobre temas técnicos e da carreira dos auditores fiscais do trabalho. Disponível para auditores fiscais do trabaIho na plataforma googlegroups.com. Acesso: 07 dez 2012. 
(NR-1) e outra (NR-28) a penalidades a serem aplicadas às empresas que descumprem itens contidos nas demais normas. Estas e outras 25 NR vêm sendo atualizadas nas três décadas que se passaram desde sua edição: Inspeção prévia (NR-2), Embargo ou interdição (NR-3), Serviços especializados em engenharia de segurança e em medicina do trabalho (NR-4), Comissão interna de prevenção de acidentes (NR-5), Equipamento de proteção individual (NR-6), Programa de controle médico de saúde ocupacional (NR-7), Edificações (NR-8), Programa de prevenção de riscos ambientais (NR-9), Segurança em instalações e serviços em eletricidade (NR-10), Transporte, movimentação, armazenagem e manuseio de materiais (NR-11), Máquinas e equipamentos (NR-12), Caldeiras e vasos de pressão (NR-13), Fornos (NR14), Atividades e operações insalubres (NR-15), Atividades e operações perigosas (NR-16), Ergonomia (NR-17), Programa de condições e meio ambiente de trabalho na indústria da construção (NR-18), Explosivos (NR-19), Líquidos combustíveis e inflamáveis (NR-20), Trabalho a céu aberto (NR-21), Segurança e saúde ocupacional na mineração (NR-22), Proteção contra incêndio (NR-23), Condições sanitárias e de conforto nos locais de trabalho (NR-24), Resíduos industriais (NR-25) e Sinalização de segurança (NR-26). Uma NR relativa ao Registro profissional do técnico de segurança do trabalho no Ministério do Trabalho (NR-27) foi revogada em 2008.

Além dessas primeiras NR, foram editadas outras sete complementares: SST portuário (NR-29), SST aquaviário (NR-30), SST na agricultura, pecuária, silvicultura, exploração florestal e aquicultura (NR-31), Segurança e saúde nos serviços de saúde (NR-32), SST em espaços confinados (NR-33), Condições e meio ambiente de trabalho na indústria da construção naval (NR-34) e SST em altura (NR-35).

Considerando que as NR têm níveis bastante distintos de abordagem do ambiente e do processo de trabalho, procurou-se, além de conhecer os dados gerais das ações de SST, destacar algumas NR selecionadas pelo autor como mais representativas de uma ação abrangente de SST.

Desse modo, por exemplo, embora a NR-7 diga respeito ao Programa de Controle Médico de Saúde Ocupacional (PCMSO), num enfoque de prevenção bem mais amplo que a primeira versão restrita aos exames médicos (MIRANDA; DIAS, 2004), e seja a norma mais fiscalizada no conjunto das ações de SST, sabe-se que muitas ações fiscais que registram itens dessa norma se restringem à verificação documental sem análise de outros aspectos de SST e sem avaliação das reais condições de trabalho. Mesmo sendo relevante, por exemplo, saber se um trabalhador foi submetido à avaliação médica antes de ser admitido, constatar que uma ação teve como único item de NR a verificação da cópia do atestado de saúde ocupacional (ASO), induz certa reserva quanto a se tratar de uma ação de SST, daí ter se buscado analisar o conjunto das ações com e sem a presença da NR-7.

Para definir uma NR como mais representativa foram consideradas aquelas mais presentes nas ações de SST ou que representam a fiscalização de um segmento econômico específico. Fez-se então a seleção das NR que para serem fiscalizadas exigem maior presença no ambiente do trabalho e dificilmente podem ser feitas apenas através da análise documental.

Desse modo, foram buscadas informações relativas às ações fiscais que envolveram o conjunto das $\mathrm{NR}$, bem como referentes às NR selecionadas pelo autor como mais representativas das ações de SST: NR-09 (PPRA); NR-12 (Equipamentos); NR-13 (Caldeiras e vasos de pressão); NR-17 (condições ergonômicas); NR-18 (construção civil); NR-22 (mineraÇão); NR-29 (aquaviário); NR-30 (portuário); NR-31 (Rural); NR-32 (Saúde); e NR-34 (Indústria Naval). As NR 05 (CIPA), 06 (EPI) e 07 (PCMSO), embora muito fiscalizadas, foram analisadas à parte em razão de tratarem por vezes de fiscalização documental fora do local de trabalho.

Considerando que todos os AFT, durante sua ação fiscal, podem verificar itens de LT e de SST, foi arbitrado pelo autor o número mínimo de 60 RI por ano por AFT (com itens de NR fiscalizados) como critério de seleção da quantidade de auditores com maior dedicação à área de SST, que chama de "equipe SST". Tal critério tem lacunas como a exclusão dos AFT que no ano de referência estavam em atividade de gestão ou em licença (saúde, maternidade etc.) e não puderam se dedicar às ações fiscais, assim como de AFT que se dedicaram a um número pequeno de grandes empresas em razão de complexidade ou dimensão dos riscos encontrados. Atribuindo dois meses a treinamentos, eventos, férias e outros afastamentos, o número de RI fixado corresponderia a uma média de seis empresas por mês. Uma vez que a mediana do número de RI por AFT que fizeram, em 2011, pelo menos um RI com item de NR é igual a 82 RI anuais (média de 92,3), espera-se que a seleção arbitrada possa compensar, do ponto de vista quantitativo, as exclusões apontadas.

\section{Aspectos éticos}

O autor é Auditor Fiscal do Trabalho. A pesquisa e análise de dados institucionais foram formalmente autorizadas pelo Diretor do Departamento de Segurança e Saúde no Trabalho (DSST) do Ministério do Trabalho e Emprego em outubro de 2012. 


\section{Resultados e discussão}

Em outubro de 2012, havia 2960 AFT no país. Os concursos realizados entre 1998 e 2010 não foram suficientes para repor as aposentadorias que têm ocorrido, pois, em 1996 havia 3423 AFT e a mediana do período 1996-2012 foi de 3052 (média de 3088) AFT, conforme dados constantes do Sfit.

O "Aviso Ministerial" no 302, de 21/12/2011, expedido pelo Ministério do Trabalho e Emprego (BRASIL, 2011b) à Ministra do Planejamento, solicitando autorização de novo concurso, informou que havia, então, 3125 Auditores Fiscais do Trabalho e que no ano seguinte 664 já cumpririam as exigências para aposentadoria e outros 109 em 2013, destacando que, ao mesmo tempo em que "decresce o número de AFT, cresce exponencialmente o número de trabalhadores e o número de estabelecimentos empregadores no Brasil”.

Até 2007, pelo número da Carteira de Identidade Fiscal (CIF) era possível saber a área de atuação da maioria dos profissionais, pois as CIF iniciadas por "40" eram relativas à carreira de Médicos do Trabalho, as iniciadas por "30" eram relativas à carreira dos Engenheiros de Segurança do Trabalho (também integrada por um número reduzido de arquitetos) e as demais, iniciadas por "0" ou "2", eram atribuídas aos Fiscais do trabalho (AFT-LEG), carreira que reunia principalmente advogados, mas várias outras formações, inclusive assistentes sociais, que constituíram anteriormente uma carreira à parte dos Fiscais do trabalho.

Dados gerenciais de junho de 2011 do chamado "sistema nacional de treinamento" da SIT registram que, dos 1934 AFT-LEG ativos naquele ano, 1033 $(53,4 \%)$ fizeram sua primeira graduação em Direito; 189 em Ciências Contábeis; 183 em Administração; 140 em variadas habilitações de Engenharia (e outros 9 em Arquitetura); 132 em Economia; 29 em profissões de saúde (Biologia, Enfermagem, Farmácia, Fisioterapia, Fonoaudiologia, Medicina, Nutrição, Odontologia, Psicologia e Veterinária); 19 em Serviço Social. Havia, em junho de 2011, 349 profissionais da carreira de Engenheiro (CIF 30) e 207 profissionais da carreira de Médico (CIF 40).

Após o concurso de 2006, a Secretaria de Inspeção do Trabalho, sob a justificativa de que as ações fiscais passariam a atender tanto a demandas de LT quanto de SST, definiu que todas as CIF passariam a se iniciar por 35 .
Embora o concurso de 2006 tenha sido planejado para dar maior peso às NR e com isso permitir o ingresso de mais profissionais com experiência ou interesse por SST, enquanto o concurso seguinte, realizado em 2010, teria dado maior peso às disciplinas de Direito para com isso ampliar o ingresso de mais profissionais com experiência ou interesse por LT, em ambos os processos seletivos o número de aprovados com formação em Direito superou aqueles com outras graduações.

Os já mencionados dados gerenciais de treinamento da SIT registram que de 356 AFT (CIF 35) aprovados no concurso de 2006, ingressados em 2007, foi identificada como primeira graduação: 132 $(37,1 \%)$ graduados em Direito, $89(25,0 \%)$ em diversas habilitações de Engenharia (inclusive 10 em Arquitetura, incluída no grupo de Engenharia tal como se fazia na CIF 30), 46 (12,9\%) em outras profissões de saúde (1 em Biologia, 1 em Farmácia, 5 em Fisioterapia, 1 em Fonoaudiologia, 12 em Medicina, 2 em Nutrição, 18 em Odontologia, 2 em Psicologia, 1 em Terapia Ocupacional e 3 em Veterinária), 9 (2,6\%) em Economia, 8 (2,4\%) em Ciências Contábeis e 6 (1,7\%) em Comunicação Social.

Com relação aos recursos orçamentários para custeio e investimento, a SIT dispunha em 2012 de uma receita de custeio e investimento de $\mathrm{R} \$$ 34.248.000,00 para todas as ações de inspeção do trabalho no país. Mas, desse total, a parcela destinada às ações de SST foi de R $\$$ 5.448.000,00 (15,9\%) (BRASIL, 2012e) ${ }^{3}$, proporção que não difere da tendência história dos recursos de SST na SIT, mas em ambas as áreas há relatos que ações deixam de ser executadas no segundo semestre de cada ano porque se esgotaram os recursos orçamentários para custeio de diárias ou passagens, além de comumente faltarem recursos para investimento e para manutenção de veículos e equipamentos.

De janeiro de 1996 a agosto de 2012, a Inspeção do Trabalho apresentou como principais resultados o resgate de 42.530 trabalhadores submetidos à condição análoga à de escravo (resultantes de 1.305 operações do Grupo Especial de Fiscalização Móvel - GEFM do Trabalho Escravo); a imposição de 65.087 embargos ou interdições em situações de risco grave e iminente à vida e à saúde; o afastamento de 118.378 crianças em situações de risco por estarem trabalhando; a inclusão no trabalho durante ação fiscal de 193.458 pessoas com deficiência e 600.653 aprendizes; além do recolhimento de cerca de 3,5 bilhões de reais em valores de FGTS recolhidos mediante ação fiscal.

\footnotetext{
${ }^{3}$ A título de comparação, nota-se que os orçamentos de custeio e investimento das agências reguladoras de Vigilância Sanitária (Anvisa) e de fiscalização dos planos de saúde (ANS) para o mesmo ano foram, respectivamente, R\$ 296.191.900,00 e R\$ 105.897.688,00 (BRASIL, 2012f).
} 
Entre 1996 e 2012, a mediana do número de ações fiscais de LT foi de 304.254 (média de 319.577/ano), enquanto que a mediana de ações fiscais de SST foi 140.796 (média de 143.033/ano). Ou seja, o número de ações de LT foi 2,2 vezes maior que das ações de fiscalização de NR, ressalvando-se que parte das ações aparece nos dois registros, pois foram verificados itens de ambas as áreas (Tabela 1).

Avaliando apenas o desempenho quantitativo, vê-se que a diferença na proporção entre o número de ações das duas áreas tem diminuído em razão da tendência de queda das ações de LT e uma relativa estabilidade das ações de SST no período, como se vê na Tabela 1.

Em 2008, em razão da Lei $n^{\circ} 11890$ (BRASIL, 2008b), a remuneração dos AFT deixou de variar em função da produtividade, como foi por 23 anos, pois foi introduzida a remuneração fixa mediante subsídio. Por conta disso, em 2009, foi desenvolvida a chamada "nova metodologia", consolidada pela Portaria Ministerial n 546 (BRASIL, 2010c), que se caracterizava pela ênfase na ação fiscal por projetos e por equipe. Esta pode ser uma das explicações dessa redução das ações de LT constatada na Tabela 1.
Outro dado para comparação entre as duas áreas é o número de autos de infração (AI) por ação fiscal. Observa-se também na tabela 1 que ambas as áreas tem apresentado uma tendência ao crescimento da proporção de AI, tendência mais acentuada na área de SST, pois houve grande crescimento em valores absolutos dos AI de SST e ocorreu queda expressiva no número de ações de LT.

Nota-se que o aumento de AI na área de LT ocorre, sobretudo, a partir de 2011. A mediana de todo o período 1996-2012 foi 107.697, próxima à média de 109.342, acentuando que havia uma estabilidade dos números absolutos até 2010. Por outro lado, a mediana dos AI de SST foi 23.280, com uma média igual a 33.733, ampliada pela tendência de elevação dos últimos cinco anos.

Outro dado que revela mudança de tendência nas ações de SST refere-se ao maior exercício, pelos AFT, do poder de embargo (paralisação total ou parcial da obra) e interdição (paralisação total ou parcial do estabelecimento, setor de serviço, máquina ou equipamento) que deve ser utilizado quando é encontrada alguma situação de grave e iminente risco à saúde e/ou integridade física do trabalhador ${ }^{4}$.

Tabela 1 Ações fiscais e autos de infração, por área da inspeção, 1996 a 2012

\begin{tabular}{ccccccc}
\hline \multirow{2}{*}{ Ano } & \multicolumn{3}{c}{ Legislação Trabalhista-LT } & \multicolumn{3}{c}{ Segurança e Saúde no Trabalho-SST } \\
& Ações & Autos & Autos por Ação & Ações & Autos & Autos por Ação \\
\hline 1996 & 404.755 & 101.485 & 0,25 & 101.108 & 23.027 & 0,23 \\
1997 & 369.315 & 121.428 & 0,33 & 140.796 & 26.691 & 0,19 \\
1998 & 315.605 & 107.697 & 0,34 & 160.949 & 23.280 & 0,14 \\
1999 & 347.380 & 101.216 & 0,29 & 162.858 & 19.091 & 0,12 \\
2000 & 353.617 & 95.828 & 0,27 & 139.515 & 17.787 & 0,13 \\
2001 & 296.741 & 93.552 & 0,32 & 127.414 & 18.105 & 0,14 \\
2002 & 304.254 & 92.988 & 0,31 & 125.390 & 17.491 & 0,14 \\
2003 & 285.241 & 103.308 & 0,36 & 129.686 & 21.585 & 0,17 \\
2004 & 302.905 & 100.413 & 0,33 & 136.881 & 20.403 & 0,15 \\
2005 & 375.097 & 107.064 & 0,29 & 166.126 & 20.538 & 0,12 \\
2006 & 357.319 & 115.085 & 0,32 & 162.058 & 24.759 & 0,15 \\
2007 & 357.788 & 113.387 & 0,32 & 157.376 & 31.467 & 0,20 \\
2008 & 299.013 & 108.722 & 0,36 & 145.815 & 40.911 & 0,28 \\
2009 & 282.377 & 113.362 & 0,40 & 158.065 & 47.936 & 0,30 \\
2010 & 255.503 & 108.253 & 0,42 & 135.621 & 58.085 & 0,43 \\
2011 & 269.253 & 135.741 & 0,50 & 138.143 & 75.628 & 0,55 \\
2012 & 256.653 & 139.283 & 0,54 & 143.760 & 86.669 & 0,60 \\
\hline
\end{tabular}

Fonte: Sistema Federal de Inspeção do Trabalho / Ministério do Trabalho e Emprego

\footnotetext{
${ }^{4}$ Situação definida na NR-3 como "toda condição ou situação de trabalho que possa causar acidente ou doença relacionada ao trabalho com lesão grave à integridade física do trabalhador".
} 
Como se vê na Tabela 2, nos últimos cinco anos houve uma tendência de ampliação do número absoluto de embargos e interdições, assim como da proporção deles em relação às ações de SST. No período 1996-2012, a mediana é igual a 3.891 (média de 3.925), mas desde 2007 o número de quatro mil embargos/interdições foi ultrapassado todos os anos, o que antes só ocorrera duas vezes. Verificou-se também o aumento da proporção de embargos/interdições em relação ao número de ações fiscais de SST, ultrapassando todos os anos, desde 2008, a razão de 3 embargos/interdições para cada 100 ações fiscais.

Filgueiras (2012) considera que o aumento do número de autos, embargos e interdições é resultado de atuação contra-hegemônica de grupos isolados de auditores que, por exemplo, atuam no GEFM do trabalho escravo, assim como de novos auditores que estariam resistindo a uma postura conciliatória que seria "síntese entre a Era Vargas (colaboração de classes) e da flexibilização contemporânea" (pg. 450). Adiante se retornará à análise de tal variação nas ações de SST.

Em relação à distribuição das ações de SST por setor econômico, observa-se uma grande concentração de ações nos setores de construção civil e comércio. Para melhor compreender tal distribuição, utilizando-se a mesma agregação de atividades econômicas que o MTE faz na divulgação das suas ações de SST, compararam-se as taxas de mortalidade por acidente do trabalho por atividade econômica, em
2010, e as ações fiscais e seus desdobramentos realizados em 2011. (Tabela 3)

No caso da Construção Civil, embora seja o agregado com quarto maior número de vínculos, compreende-se porque é o segundo setor mais fiscalizado e de longe o que tem maior número de autos e embargos/interdições, afinal foi setor com o segundo maior número de óbitos e a terceira maior taxa de mortalidade. (Tabela 3)

No setor de Comércio, embora apresente o maior número de vínculos e o maior número absoluto de óbitos, a taxa de mortalidade é das mais baixas, o que não justificaria que fosse o setor mais fiscalizado. Já os setores da Indústria Mineral (que inclui a extração de petróleo) e de Transportes, com as maiores taxas de mortalidade, apresentam baixo número de ações fiscais e, assim, poucas análises de acidentes desenvolvidas. A maior facilidade de acesso às empresas do Comércio parece ser um dos fatores que estimulam sua maior fiscalização. (Tabela 3)

Quase 30\% das análises de acidentes são feitas na Construção Civil (Tabela 3), enquanto no setor de comércio foram feitas mais análises que nos dois com as maiores taxas de mortalidade (Indústria Mineral e Transportes). O fato dos acidentes nesses dois setores ocorrerem principalmente em áreas rurais ou periféricas seria um dos elementos explicativos dessa menor priorização, que envolveria maior dispêndio de tempo e recursos para deslocamento.

Tabela 2 Embargos e interdições e ações de SST, 1996 a 2012

\begin{tabular}{cccc}
\hline Ano & Ações SST & $\begin{array}{c}\text { Embargos } \\
\text { elnterdições }\end{array}$ & Razão* \\
\hline 1996 & 101.108 & 1.918 & 1,9 \\
1997 & 140.796 & 2.511 & 1,8 \\
1998 & 160.949 & 3.611 & 2,2 \\
1999 & 162.858 & 4.474 & 2,7 \\
2000 & 139.515 & 4.261 & 3,1 \\
2001 & 127.414 & 3.891 & 3,1 \\
2002 & 125.390 & 3.621 & 2,9 \\
2003 & 129.686 & 3.261 & 2,5 \\
2004 & 136.881 & 3.635 & 2,7 \\
2005 & 166.126 & 3.743 & 2,3 \\
2006 & 162.058 & 3.857 & 2,4 \\
2007 & 157.376 & 4.139 & 2,6 \\
2008 & 145.815 & 4.488 & 3,1 \\
2009 & 158.065 & 5.304 & 3,4 \\
2010 & 135.621 & 4.602 & 3,4 \\
2011 & 138.143 & 4.512 & 3,3 \\
2012 & 143.760 & 4.889 & 3,4 \\
\hline
\end{tabular}

* Razão: Embargos e interdições por 100 ações em SST

Fonte: Sistema Federal de Inspeção do Trabalho / Ministério do Trabalho e Emprego 
Tabela 3 Taxa de mortalidade por acidente do trabalho em 2010 e ações fiscais do MTE em 2011, segundo atividade econômica

\begin{tabular}{|c|c|c|c|c|c|c|c|}
\hline Atividade Econômica & $\underset{*}{\text { Vínculos }}$ & $\begin{array}{c}\text { Óbitos } \\
*\end{array}$ & $\begin{array}{c}\text { Taxa Mortalidade } \\
\text { (por } 100 \text { mil vínculos } \\
\text { empregatícios) } \\
*\end{array}$ & Ações & $\underset{\text { 粎 }}{\text { Autos }}$ & $\begin{array}{l}\text { Embargose } \\
\text { Interdições } \\
\text { ****⿲二丨匕 }\end{array}$ & $\begin{array}{c}\text { Análise } \\
\text { de Acidentesdo } \\
\text { Trabalho } \\
\text { 米米 }\end{array}$ \\
\hline Indústria mineral & 546.518 & 129 & 23,60 & 3163 & 4374 & 167 & 86 \\
\hline $\begin{array}{l}\text { Transporte, armazen- } \\
\text { agem e correios }\end{array}$ & 1.998 .355 & 417 & 20,87 & 6522 & 2316 & 51 & 97 \\
\hline Construção civil & 2.587 .170 & 438 & 16,93 & 31828 & 27784 & 2937 & 581 \\
\hline $\begin{array}{l}\text { Indústria de madeira e } \\
\text { papel }\end{array}$ & 346.437 & 46 & 13,28 & 2335 & 989 & 59 & 54 \\
\hline Agricultura & 1.522 .092 & 174 & 11,43 & 10324 & 9585 & 176 & 99 \\
\hline $\begin{array}{l}\text { Ind. Alimentos e } \\
\text { bebidas }\end{array}$ & 1.501 .494 & 164 & 10,92 & 4005 & 3637 & 139 & 149 \\
\hline Ind. Química & 973.176 & 92 & 9,45 & 3046 & 2393 & 69 & 88 \\
\hline Ind. Metal & 2.130 .897 & 178 & 8,35 & 6797 & 5298 & 324 & 238 \\
\hline Indústrias - Outras & 522.834 & 36 & 6,89 & 2081 & 889 & 27 & 42 \\
\hline Comércio & 7.790 .655 & 451 & 5,79 & 36769 & 8406 & 324 & 203 \\
\hline Serviços & 5.085 .423 & 266 & 5,23 & 8046 & 3183 & 97 & 161 \\
\hline Ind. Tecido e couro & 1.420 .553 & 51 & 3,59 & 5035 & 1832 & 47 & 52 \\
\hline Hotéis e restaurantes & 144.5931 & 40 & 2,77 & 6835 & 1010 & 18 & 32 \\
\hline Outros & 513.2130 & 124 & 2,42 & 3448 & 1170 & 39 & 41 \\
\hline Instituições financeiras & 748.813 & 16 & 2,14 & 1228 & 455 & 8 & 5 \\
\hline Saúde & 1.490 .208 & 28 & 1,88 & 4237 & 1923 & 27 & 25 \\
\hline Educação & 1.300 .342 & 20 & 1,54 & 2444 & 384 & 3 & 4 \\
\hline Ignorado & - & 42 & - & 0 & 0 & 0 & 0 \\
\hline Total & 36543028 & 2712 & - & 138143 & 75628 & 4512 & 1957 \\
\hline
\end{tabular}

* Dados referentes a 2010 .

橉 Dados referentes a 2011.

Fonte: Dataprev, CAT / Ministério da Previdência Social; Sistema Federal de Inspeção do Trabalho / Ministério do Trabalho e Emprego

Analisando os dados da Tabela 4, em relação à incapacidade permanente, verifica-se que o setor de Comércio não apresenta taxa tão elevada quanto aos demais setores. Contudo, se observa que os dois setores que têm as maiores taxas de mortalidade possuem também taxas elevadas de incapacidade permanente, superados aqui pela Indústria de Madeira e Papel, que aparece na Tabela $3 \mathrm{com}$ a quarta maior taxa de mortalidade, sendo relativamente pouco fiscalizada. Mais uma vez se observa uma inversão em relação ao que deveria ser prioritário fiscalizar, algo a merecer medidas de gestão nacional e regionais.

Com relação à composição profissional da equipe de AFT, utilizando-se a base de dados do MTE, com 3125 profissionais ativos em 2011, aplicou-se o critério do mínimo de 60 RI por AFT, por grupos selecionados de NR, alcançando a distribuição por CIF que consta na Tabela 5, na qual também se apresentam os totais de RI emitidos, segundo grupos de NR fiscalizadas em 2011.

A Tabela 5 mostra que, quando são consideradas apenas as NR relativas a Máquinas e Equipamentos (NR-12), Caldeiras e Vasos de Pressão (NR13), Ergonomia (NR-17), Construção Civil (NR-18), Mineração (NR-22), Rural (NR-31) e Estabelecimentos de Saúde (NR-32) (componentes do grupo A da tabela), o número total de RI referentes à 2011 (emitidos pelos AFT que fizeram o mínimo de 60) é de 86.116. Este número cresce mais de $30 \%$ no grupo B, quando é incluída a NR de Programa de Riscos Ambientais (NR-9), esta por vezes limitada à mera análise documental. 
Tabela 4 Incapacidade permanente por acidente do trabalho em 2010, segundo atividade econômica

\begin{tabular}{lccc}
\hline \multicolumn{1}{c}{ Atividade Econômica } & Vínculos & $\begin{array}{c}\text { Incapacidade } \\
\text { Permanente }\end{array}$ & $\begin{array}{c}\text { Taxa de Incapacidade } \\
\text { Permanente (por 10 mil) }\end{array}$ \\
\hline Indústria de Madeira e Papel & 346.437 & 381 & 11,00 \\
Indústria Mineral & 546.518 & 392 & 7,17 \\
Transporte, armazenagem e correios & 1.998 .355 & 1.110 & 5,55 \\
Indústrias - Outras & 522.834 & 262 & 5,01 \\
Ind. Alimentos e bebidas & 1.50 .1494 & 700 & 4,66 \\
Ind. Metal & 2.130 .897 & 921 & 4,32 \\
Ind. Químicos & 973.176 & 419 & 4,31 \\
Construção & 2.587 .170 & 990 & 3,83 \\
Instituições financeiras & 748.813 & 280 & 3,74 \\
Ind. Tecido e Couro & 1.420 .553 & 363 & 2,56 \\
Agricultura & 1.522 .092 & 382 & 2,51 \\
Serviços & 5.085 .423 & 1.159 & 2,28 \\
Comércio & 7.790 .655 & 1.548 & 1,99 \\
Hotéis e restaurantes & 1.445 .931 & 285 & 1,97 \\
Saúde & 1.490 .208 & 207 & 0.80 \\
Outros & 5.132 .130 & 701 & \\
Educação & 1.300 .342 & 104 & \\
Ignorado & - & 3.893 & \\
Total & 36.543 .028 & 14.097 & \\
\hline Fon & 509 & \\
\hline
\end{tabular}

Fonte: Dataprev, CAT / Ministério da Previdência Social; Sistema Federal de Inspeção do Trabalho / Ministério do Trabalho e Emprego

Tabela 5 Subgrupos deAuditores Fiscais do Trabalho (AFT) com mais de 60 Relatórios de Inspeção (RI) anuais, segundo Carteira de Identidade Fiscal (CIF) e grupo de NR fiscalizada em 2011

\begin{tabular}{|c|c|c|c|c|c|c|}
\hline Grupos de NR & Total de $R I^{1}$ & AFT CIF $30^{2}$ & AFT CIF $40^{3}$ & AFT CIF LEG ${ }^{4}$ & AFT CIF $35^{5}$ & Total AFT \\
\hline A & 86116 & 209 & 91 & 33 & 254 & 587 \\
\hline B & 110149 & 243 & 115 & 210 & 316 & 884 \\
\hline C & 113597 & 245 & 116 & 222 & 319 & 902 \\
\hline $\mathrm{D}$ & 180666 & 256 & 131 & 516 & 419 & 1322 \\
\hline \multicolumn{7}{|c|}{ Grupo A: NR-12 ou 13 ou 17 ou 18 ou 22 ou 31 ou 32; } \\
\hline \multicolumn{7}{|c|}{ Grupo B: Grupo A + NR-9; } \\
\hline \multicolumn{7}{|c|}{ Grupo C: Grupo B + NR 29, 30 ou 34; } \\
\hline \multicolumn{7}{|c|}{ Grupo D: Grupo C + NR 5, 6 ou 7.} \\
\hline \multicolumn{7}{|c|}{${ }^{1}$ Emitidos por AFT com mais de $60 \mathrm{RI}$ anuais. } \\
\hline \multicolumn{7}{|c|}{${ }^{2} \mathrm{CIF} 30$ - Engenheiros de Segurança do Trabalho } \\
\hline \multicolumn{7}{|c|}{${ }^{3}$ CIF 40 - Médicos do Trabalho } \\
\hline \multicolumn{7}{|c|}{${ }^{4}$ CIF LEG - Advogados e outros profissionais } \\
\hline \multicolumn{7}{|c|}{${ }^{5}$ CIF 35 - Formações variadas (após 2007) } \\
\hline Fonte: Sistema F & leral de Inspe & o do Trabalh & Ministério d & abalho & 0 & \\
\hline
\end{tabular}


Não ocorre grande aumento do número de RI com a inclusão das NR relacionadas ao trabalho portuário (NR-29), aquaviário (NR-30) e de construção naval (NR-34) (grupo C), diferente do que se constata com a inclusão das NR relativas à CIPA (NR-5), EPI (NR6) e PCMSO (NR-7) (grupo D) - aumenta em quase $65 \%$ o número de RI em relação ao grupo B (soma do grupo A com a NR-9) (Tabela 5). Ou seja, a quantidade de ações de SST somente se amplia quanto exige menos atuação no ambiente de trabalho e/ou se restringe à análise de documentos.

Nota-se que os CIF 30 e CIF 40 não têm grande variação entre os grupos de NR, o que ocorre com os demais grupos, especialmente os CIF LEG, quando se incluem as NR-5, NR-6 e NR-7, que aumentam o número de RI no Grupo D em mais de 130\% em relação ao grupo C. Entre os mesmos grupos de NR, os CIF 35 ampliam a quantidade de RI em $30 \%$. (Tabela 5)

É possível se afirmar, portanto, que os AFT das CIF 30 e 40 estudados têm, em geral, maior atuação em NR mais identificadas com a inspeção de ambientes do trabalho, especialmente em relação aos CIF LEG.

De modo a estimar o número de AFT que se dedicam prioritariamente à SST, considerou-se, com base nos dados da Tabela 5, que os grupos B (884 AFT) e C (902 AFT) representam melhor as ações fiscais de SST em que se verificou o ambiente de trabalho, e se verificou a média do número de AFT que os compõem (893). Fazem parte deste grupo atuante em SST os AFT LEG, cuja média dos grupos B (210) e C (222) é de 216. Tendo em conta que pelo menos metade desses AFT LEG atuam e registram RI conjunto com AFT com outra inserção, mas se dedicam na ação apenas aos chamados "atributos" de legislação trabalhista, considerou-se excluir a metade da média dos AFT LEG dos grupos B e C, ou seja, 108 AFT LEG, de modo a manter na "Equipe SST" apenas a parcela que se considerou ter maior dedicação às ações relacionadas ao tema. Desse modo, estimou-se que os AFT que se dedicam prioritariamente à SST totalizaram 785 auditores $^{5}$, realizando ações que fiscalizam efetivamente o ambiente de trabalho. Este número, que não inclui os AFT que ocupam função de gestão ou atuam na sede da SIT em Brasília, representava apenas 25\% do total dos 3125 AFT ativos no país no final de 2011.

Para este grupo de 785 AFT ("Equipe SST"), a partir dos dados constantes na Tabela 5, estimou-se que haveria: 317,5 (40,45\%) AFT CIF 35; 244 (31,08\%) CIF 30 - antigos Engenheiros; 115,5 (14,71\%) AFT CIF 40 - antigos médicos do trabalho;108 (13,76\%) CIF LEG.

Dos AFT CIF 35 dessa "Equipe SST", foi possível identificar a primeira graduação de 194 que ingres- saram em 2007: 63 (32,5\%) se graduaram em Direito, 61 (31,4\%) são engenheiros (nas suas várias habilitações e ainda 6 arquitetos), 23 (11,9\%) de profissões de saúde (9 odontólogos e 4 médicos são os mais prevalentes), 14 (7,2\%) graduados em Administração, 6 $(3,1 \%)$ em Comunicação Social, 5 (2,6\%) em Ciências Contábeis e $5(2,6 \%)$ em Economia.

Em relação aos 356 que ingressaram em 2007 com CIF 35 e dos quais se obteve dados de primeira graduação, pode se constatar que $47,7 \%$ dos graduados em Direito integram o grupo mais ativo em SST, enquanto, entre os engenheiros e arquitetos, a proporção foi de $68,5 \%$. Dentre os profissionais com primeira graduação na área de saúde, 50,0\% estão na "Equipe SST", proporção que chegou a 62,5\% entre os graduados em Ciências Contábeis, 55,5\% em Economia e 100,0\% em Comunicação.

Evidenciou-se que o grupo de engenheiros e arquitetos, embora representasse apenas 25,0\% do total que ingressou no concurso de 2007, atingiu $31,4 \%$ na amostra selecionada. Somado aos 244 AFT com CIF 30, esse grupo soma 305 AFT com formação em engenharia e arquitetura, totalizando $38,9 \%$ do corpo efetivo de atuação em SST.

Deve-se destacar que, dos 140 AFT LEG ativos em 2011 e com formação em engenharia ou arquitetura, apenas 17 constaram na lista dos mais atuantes em SST, demonstrando que não basta uma determinada qualificação, mas também e principalmente que seja atribuída a tais profissionais a atuação prioritária em SST.

Como se viu, o staff federal brasileiro de auditores atuantes em SST reúne apenas 785 AFT. É insuficiente, como é o quadro total da Inspeção do Trabalho, segundo parâmetros técnicos da OIT, que, ao tratar da inspeção do trabalho, consideram que o número adequado de auditores-fiscais do trabalho, em relação ao número de trabalhadores, deveria seguir a seguinte proporção: a) para economias de mercado industrializadas - 1/10000; b) para economias em processo rápido de industrialização -1/15000; c) para economias em transição - 1/20000; d) para economias em processo atrasado de desenvolvimento 1/40000 (INTERNATIONAL LABOUR OFFICE, 2006, p. 66). Seguindo tais orientações e considerando que o Brasil estaria hoje migrando da situação 'c' para a situação 'b', ou seja, 1 AFT na proporção de 15000 a 20000 trabalhadores, possuindo uma população economicamente ativa de 120 milhões de brasileiros, isso resultaria que o país deveria ter entre 6000 e 8000 AFT, ou seja, deveria ter de 3040 a 5040 novos AFT (além dos existentes em outubro de 2012). 
Um estudo realizado pelo IPEA (BARBOSA; CORSEUIL; REIS, 2012) para o sindicato dos AFT, utilizando critérios relacionados com as principais atividades que desempenham, estimou que "havendo prioridade para a redução de acidentes de trabalho", o aumento total no número de AFT no território brasileiro "teria que ser de 5273 novos funcionários num período de quatro anos".

O estudo, todavia, constatou que a questão essencial não se restringe ao número de AFT que atuam prioritariamente em SST. É possível afirmar que o modelo institucional misto de Inspeção do Trabalho tem resultado na formação de uma equipe não apenas insuficiente, mas de formação imprecisa, com ações na maior parte das vezes genéricas e que não se destinam aos setores mais estratégicos do ponto de vista epidemiológico. Exceção se faz à Construção Civil, setor de grande relevância para a inspeção de SST também em outros países, como nos EUA, onde ocupa cerca de $40 \%$ da jornada de trabalho dos inspetores da OSHA (WEIL, 2008).

A análise da distribuição dos RI por grupos de NR demonstrou a exagerada influência das ações em que predominam as análises documentais, com baixa presença no ambiente de trabalho, especialmente em relação aos CIF LEG, mas também aos CIF 35. Ressalte-se que os AFT com CIF 30 e CIF 40 que estão na "equipe SST" selecionada têm atuação mais significativa nas NR consideradas de maior presença no ambiente de trabalho.

Chamou atenção o fato dos engenheiros (e arquitetos) que ingressaram na carreira $\mathrm{CIF} 30$, mas também os que ingressaram como CIF 35, terem maior adesão às ações de SST, o que não ocorre com aqueles engenheiros (e arquitetos) que ingressaram como CIF LEG, o que expressa que a combinação entre a formação e uma gestão que lhes oriente ou permita priorizar as ações de SST é fundamental para que se desenvolvam nas ações de SST. A falta de prioridade da gestão em relação à SST volta a aparecer no fato que, dentre os CIF 35 que ingressaram em 2007, os profissionais com formação na área de Saúde não têm presença significantemente maior que os graduados em Direito na composição do grupo mais ativo em SST.

Por outro lado, apesar da forte presença dos AFT CIF 30 no grupo mais ativo, a crescente aposentadoria dos CIF 30 e CIF 40, faz com que a "Equipe SST" seja marcantemente composta pelos AFT CIF $35(40,5 \%)$, mas a maioria destes tem sido progressivamente destinada às ações da área de LT.

É frequente que AFT critiquem certo "culto ao generalista” que teria predominado após a criação da CIF 35, cujos AFT passaram a ser frequentemente denominados "flex" em razão do ecletismo deles esperado - capazes de fiscalizar tanto LT quanto SST, de forma considerada superficial (AFTBRASIL, 2012), mas não encontramos evidência que a questão da maior ou menor aprofundamento das ações fiscais possa ser explicada apenas com base nesta variável.

Entretanto, é possível estimar que, mantido o atual modelo, a atuação do MTE em SST tende a ter uma atuação cada vez mais superficial e documental, com uma equipe de reduzida proporção que se forma mais devido a fatores e interesses individuais que a uma política de seleção e formação de recursos humanos que atenda às necessidades de uma atuação mais direcionada à redução dos acidentes e doenças do trabalho no país.

Embora haja significativa presença de graduados em Direito na "Equipe SST", não pode ser visto como positivo que o sistema atual, mesmo quando diz priorizar o ingresso de profissionais de SST, privilegie o ingresso de advogados em detrimento de profissionais com formação nas áreas de saúde ou de engenharia, o que favorece a manutenção da hegemonia histórica da área de LT.

Constatou-se que a estabilidade no número de ações consideradas de SST no período 1996-2012, com mediana maior que $140 \mathrm{mil}$ ao ano, se baseia em grande medida na decisão de conceituar como ação de SST aquela cujo RI inclua apenas uma ementa de NR. Desse modo, em uma ação onde se priorize, por exemplo, a análise de documentos para fiscalizar FGTS, bastaria a análise de um Atestado de Saúde Ocupacional - ASO para que também fosse considerada como ação de SST, com igual importância estatística que uma ação que fiscalizasse, por exemplo, uma centena de vasos de pressão numa indústria ou as condições ergonômicas que levam ao adoecimento dos trabalhadores de um banco. Há que se considerar ainda que a relativa estabilidade dessas ações de SST está em contradição com o grande crescimento da massa de trabalhadores do país na última década, a ampliação da complexidade dos processos de trabalho e produção e a incorporação de novas tecnologias.

Quanto ao crescimento da proporção de autos de infração, indica que as ações fiscais não têm conseguido coibir as irregularidades, o que estaria levando ao aumento na média de autuação, sobretudo nas ações de SST. Vários outros fatores podem ter contribuído para tal variação, tais como: constatação de que é necessário haver o crescimento das "práticas coercitivas" (FILGUEIRAS, 2012) em relação às "práticas pedagógicas" enfatizadas por Pires (2009); existência de maior cobrança de punição aos infratores por parte da sociedade; ingresso na última década de grande número de AFT 
que não conviveram com o período da ditadura militar em que havia restrições gerenciais à autuação; maior facilidade de lavratura com a utilização de meios eletrônicos em substituição à lavratura grafada à mão etc.

Ainda que se constate um expressivo aumento do número de autos de infração no período, não se pode afirmar que estes sejam excessivos, pois fica evidente que a grande maioria das ações fiscais não resulta em autuação.

Apesar de o art. 628 da CLT determinar que cada violação de preceito legal encontrada deva corresponder à lavratura de um auto, sob pena de responsabilidade, ainda é grande a variação de comportamento dos AFT em relação às condutas prescritas por leis e regulamentos, numa expressiva demonstração da "discricionariedade das burocracias" (PIRES, 2009). Como exemplo, Bastos (2012), ao analisar a atuação dos AFT em 2009, identificou que dentre as empresas encontradas com empregados sem registro, 90,8\% optaram por registrá-los sob ação fiscal, mas apenas $6,7 \%$ destes estabelecimentos foram autuados.

Como destacam Cardoso e Lage (2007), a atitude do empregador "é uma função direta da probabilidade de ele ser apanhado burlando a lei e da sanção que lhe será aplicada por não-cumprimento" (pg. 71). Assim sendo, se avalia que o risco de ser fiscalizado é baixo e, quando o é, recebe uma sanção de baixo valor pecuniário, como em geral são as multas trabalhistas, sua tendência seria descumprir a lei. Fundamentado nesses autores, é possível afirmar que o crescimento do nível de autuações, ainda que as multas sejam de valor relativamente baixo e demorem em ser cobradas, elevaria o risco percebido de sanção e poderia modificar a atitude dos empregadores.

Em relação ao aumento dos embargos/interdições, parece ser um fenômeno associado à elevação das autuações, reforçado pela ênfase nas ações de fiscalização da Construção Civil, onde ocorre a grande maioria dos embargos, e, provavelmente, também pelo aumento das interdições em razão das recentes inovações na NR-12 para proteção dos trabalhadores em relação às máquinas e equipamentos.

Os embargos/interdições não são sanção, mas sim medida cautelar diante de uma situação de risco grave e iminente. Geralmente só ocorrem embargos/interdições em relação ao risco de acidentes do trabalho e pouco em relação às doenças, possivelmente devido à evolução de largo prazo destas e talvez à pouca formação clínico-epidemiológica da maioria dos AFT.

\section{Conclusões e recomendações}

Muitas ações de SST não são planejadas com base em critérios epidemiológicos, pois, como se viu, setores com elevadas taxas de mortalidade ou de invalidez como os setores de Indústria Mineral, Transportes e Indústria da Madeira e Papel são relativamente pouco fiscalizados, o que poderia ser atribuído também à gestão inadequada dos escassos recursos humanos e financeiros existentes, levando a serem priorizadas as ações fiscais urbanas e em pequenas empresas, especialmente do Comércio.

O presente estudo permite concluir que o MTE, com sua atual estrutura e modo de ação, não tem condições de enfrentar adequadamente o grave quadro de doenças e acidentes do trabalho do país. Torna-se necessário discutir o atual modelo e adotar medidas visando o fortalecimento da SST, o que poderia se dar na atual estrutura, na recriação de uma instância específica ou mesmo na criação de uma agência autônoma dedicada exclusivamente à SST, tal como existe em países como Espanha, Reino Unido e Estados Unidos.

Em qualquer das opções é preciso ampliar o quadro de AFT dedicados a SST, oferecendo-lhes qualificação em áreas afins, como Higiene e Segurança do Trabalho e Saúde do Trabalhador, assim como assegurar que as ações de SST tenham a amplitude técnica necessária para coibir e controlar a exposição dos trabalhadores a situações de risco e, em especial, evitar as mortes e lesões incapacitantes, em sua grande maioria evitáveis.

Embora seja positiva a edição da Política e do Plano Nacional de Segurança e Saúde no Trabalho (respectivamente, PNSST e Plansat) (BRASIL, $2012 \mathrm{~g}$ ), que fixaram diretrizes, objetivos e ações conjuntas para os Ministérios do Trabalho e Emprego, da Previdência Social e da Saúde, é preciso aprofundar as possibilidades de cooperação entre os diferentes órgãos que atuam na área, nas três esferas, assim como construir também no MTE um Plano de Ação para SST que seja suficientemente ambicioso para cumprir seu papel na mudança da "história natural dos acidentes e doenças do trabalho" no país.

Outros estudos e reflexões sobre a práticas dos AFT poderiam ser desenvolvidos, assim como pesquisas que aprofundem a análise dos modelos regulatórios desenvolvidos no país, de modo a colher novos elementos para as políticas públicas de prevenção de acidentes e doenças do trabalho. 


\section{Agradecimentos}

O autor agradece a Carlos Alberto Virgílio de Andrade (MTE) e a Jeferson Seidler (MTE) pela relevante contribuição na coleta e crítica dos dados.

\section{Referências}

BARBOSA, A. L. N. H.; CORSEUIL, C. H. L.; REIS, M. C. A. Necessidade de Auditores-Fiscais do Trabalho no Brasil: uma análise contemplando o grau de descumprimento da legislação trabalhista. Brasília, DF: IPEA, jul. 2012. (Nota Técnica n. 4). Disponível em: <http://www.ipea.gov.br/portal/images/stories/PDFs/ nota_tecnica/nota_tecnicaxxxxxxx.pdf $>$. Acesso em 21 abr. 2013.

BASTOS, E. M. Da potencialização do impacto da inspeção do trabalho no Brasil. Brasília: Secretaria de Inspeção do Trabalho, Ministério do Trabalho e Emprego, 2012.

BRASIL. Decreto n ${ }^{0}$ 1313, de 17 de janeiro de 1891. Estabelece providências para regularizar o trabalho dos menores empregados nas fábricas da Capital Federal. Disponível em: <http://www2.camara.leg.br/legin/fed/ decret/1824-1899/decreto-1313-17-janeiro-1891-498588publicacaooriginal-1-pe.html> . Acesso em: 01 dez. 2012.

BRASIL. Decreto n ${ }^{\circ} 19671 A$, de 4 de Fevereiro de 1931. Dispõe sobre a organização do Departamento Nacional do Trabalho, creado pelo Decreto ${ }^{\circ}$ 19.667, de 4 de fevereiro de 1931. Diário Oficial da União - Seção 1 - 7/2/1931, Página 1879. Disponível em: <http://www2.camara.leg.br/legin/fed/ decret/1930-1939/decreto-19671a-4-fevereiro-1931560132-publicacaooriginal-82744-pe.html>. Acesso em: 15 jun. 2014.

BRASIL. Decreto-Lei n ${ }^{\circ}$ 6479, de 9 de maio de 1944. Cria carreiras no Quadro Único do Ministério do Trabalho, Indústria e Comércio, e dá outras providências. Disponível em: < http://www.planalto. gov.br/ccivil_03/decreto-lei/1937-1946/Del6479.htm>. Acesso em: 08 dez. 2012.

BRASIL. Decreto n ${ }^{\circ}$ 55841, de 15 de Março de 1965. Aprova o Regulamento da Inspeção do Trabalho. Disponível em: <http:/www2.camara.leg.br/legin/ fed/decret/1960-1969/decreto-55841-15-marco-1965396342-norma-pe.html>. Acesso em: 15 jun. 2014.

BRASIL. Decreto $n^{\circ}$ 95461, de 11 de dezembro de 1987. Revoga o Decreto ${ }^{\circ}$ 68796, de 23 de junho de 1971, e revigora o Decreto $n^{\circ} 41721$, de 25 de junho de 1957, concernentes à Convenção $n^{\circ} 81$, da Organização Internacional do Trabalho. Disponível em: < http://www.planalto.gov.br/ccivil_03/decreto/ Antigos/D95461.htm>. Acesso em: 15 jūn. 2014.

BRASIL. Constituição Federal (1988). Texto consolidado até a Emenda Constitucional no 81, de 05 de junho de 2014. Disponível em: <http:// www.senado.gov.br/legislacao/const/con1988/ CON1988_05.06.2014/index.shtm >. Acesso em: 09 jun. 2014.

BRASIL. Instrução Normativa Intersecretarial $n^{0} 10$, de 5 de julho de 1995. Disponível em: < http://pesquisa. in.gov.br/imprensa/jsp/visualiza/index.jsp?jornal=1\&pa gina $=25 \&$ data $=13 / 07 / 1995>$. Acesso em: 02 dez. 2012 .

BRASIL. Decreto $n^{\circ} 3129$, de 9 de agosto de 1999. Aprova a Estrutura Regimental e o Quadro Demonstrativo dos Cargos em Comissão e Funções Gratificadas do Ministério do Trabalho e Emprego, e dá outras providências. Disponível em: < http://www. planalto.gov.br/ccivil_03/decreto/D3129.htm>. Acesso em: 15 jun. 2014.

BRASIL. Decreto ${ }^{\circ} 4552$, de 27 de dezembro de 2002a. Aprova o Regulamento da Inspeção do Trabalho. Disponível em: < http://www.planalto.gov. br/ccivil_03/decreto/2002/d4552.htm >. Acesso em: 15 jun. $201 \overline{4}$.

BRASIL. Lei $n^{\circ}$ 10593, de 6 de dezembro de 2002b. Dispõe sobre a reestruturação da Carreira Auditoria do Tesouro Nacional, que passa a denominarse Carreira Auditoria da Receita Federal - ARF, e sobre a organização da Carreira Auditoria-Fiscal da Previdência Social e da Carreira Auditoria-Fiscal do Trabalho, e dá outras providências. Disponível em: <http://www.planalto.gov.br/ccivil_03/LEIS/2002/ L10593.htm>. Acesso em: 15 jun. 2014.

BRASIL. Ministério do Trabalho e Emprego. Sistema Federal de Inspeção do Trabalho: manual do usuário. Brasília: MTE, CGI, SIT, 2008a.

BRASIL. Lei n ${ }^{\circ}$ 11.890, de 24 de dezembro de 2008b. Dispõe sobre a reestruturação da composição remuneratória das Carreiras de Auditoria da Receita Federal do Brasil e Auditoria-Fiscal do Trabalho (...). Disponível em: <http://www.planalto.gov.br/ ccivil_03/_Ato2007-2010/2008/Lei/L11890.htm>. Acesso em: 15 jun. 2014.

BRASIL. Ministério da Saúde. Secretaria de Ciência, Tecnologia e Insumos Estratégicos. Departamento de Ciência e Tecnologia. Doenças negligenciadas: estratégias do Ministério da Saúde. Revista de Saúde Pública, São Paulo, v. 44, n. 1, p. 200-202, 2010a.

BRASIL. Resolução MPS/CNPS no 1316, de 31 de maio de 2010. Diário Oficial [da] União, Seção 1, p. 84, 14 jun. 2010b. 
BRASIL. Ministério do Trabalho e Emprego. Portaria $\mathrm{n}^{\mathrm{O}}$ 546, de 11 de março de 2010. Diário Oficial [da] União, Seção 1, p. 99, 12 de mar. 2010c.

BRASIL. Ministério da Previdência Social. Ministério do Trabalho e Emprego. Anuário Estatístico de Acidentes do Trabalho: AEAT 2009, v. 1, Brasília, 2011a. <http://www.previdencia.gov.br/estatisticas/ anuario-estatistico-de-acidentes-do-trabalho-2009>. Acesso em: 09 jun. 2014.

BRASIL. Ministério do Trabalho e Emprego. Aviso Ministerial n 302 , Comunicação do Ministro do Trabalho à Ministra do Planejamento. Brasília, DF: MTE, 21 dez. 2011b.

BRASIL. Ministério da Previdência Social; Ministério do Trabalho e Emprego. Anuário Estatístico de Acidentes do Trabalho: AEAT 2011, v. 1, 2011, Brasília, 2012a. Disponível em: < http://www.previdencia.gov. br/aeat-2011>. Acesso em: 09 jun. 2014.

BRASIL. Ministério da Previdência Social. Anuário Estatístico da Previdência Social: Suplemento Histórico (1980 a 2011). Brasília: MPS/DATAPREV, 2012 b.

BRASIL. Advocacia-Geral da União. Parecer no. 508/2012/CONJUR-MTE/CGU/AGU. Processo 47703.000291/2012-24. Brasília, DF: AGU, 2012c. Disponível em: < https://www.sinait.org.br/docs/ PARECER508_2012CONJUR_MTE_CGU_AGU.pdf > Acesso em: 11 jun. 2014.

BRASIL. Ministério do Trabalho e Emprego. Secretaria de Inspeção do Trabalho. Diretrizes para o Planejamento 2012 - 2015. Brasília: MTE, 2012d.

BRASIL. Ministério do Trabalho e Emprego. Secretaria de Inspeção do Trabalho. Execução Orçamentária / Financeira. Brasília: MTE, 23 out. 2012e.

BRASIL, Lei no 12595, de 19 de Janeiro de 2012. Estima a receita e fixa a despesa da União para o exercício financeiro de 2012. Suplemento ao $\mathrm{n}^{\mathrm{o}}$ 15. Diário Oficial da União de 20 de Janeiro de 2012f. Disponível em: <http:/www.planalto.gov.br/ ccivil_03/_Ato2011-2014/2012/Lei/L12595.HTM>. Acesso em: 09 jun. 2014.

BRASIL. Ministério do Trabalho e Emprego. Ministério da Previdência Social. Ministério da Saúde. Plano Nacional de Segurança e Saúde no Trabalho (anexo com Política Nacional de Segurança e Saúde do Trabalhador - PNSST). Brasília, 2012g. Disponível em: <http:/portal.mte.gov.br/lumis/portal/file/ fileDownload.jsp?fileId=8A7C816A36A27C14013733 566EB57D78>. Acesso em 15 jun. 2014.

CARDOSO, A.; LAGE, T. As normas e os fatos. Rio de Janeiro: Editora FGV, 2007.

DONATO, M. P. Curso de direito individual do trabalho. São Paulo: LTr, 2008.
FILGUEIRAS, V. A. Estado e direito do trabalho no Brasil: regulação do emprego entre 1988 e 2088. $471 \mathrm{f}$. Tese (Doutorado em Ciências Sociais) - Faculdade de Filosofia e Ciências Humanas, Universidade Federal da Bahia, Salvador, 2012.

HEALTH AND SAFETY EXECUTIVE. Health and safety $\backslash$ Statistics 2008/09. National Statistics, Disponível em: <http://www.hse.gov.uk/statistics/ overall/hssh0809.pdf>. Acesso em 02 dez 2012.

GONZÁLEZ, F. S. La inspección de trabajo. In: LOZANO, N. B.; VALENZUELA, E. M. (org.) Instituciones de Derecho del Trabajo y de la Seguridad Social. 1. ed. Ciudad de México: Academia Iberoamericana de Derecho del Trabajo y de la Seguridad Social / Universidad Nacional Autónoma de México, 1997. cap. 43, p. 783-802.

INTERNATIONAL LABOUR OFFICE. Part XIII of the Treaty of Peace of Versailles. Official Bulletin. Volume I. April 1919 - August 1920. Geneve: ILO, 1923. Disponível em: < http://www.ilo.org/public/english/ bureau/leg/download/partxiii-treaty.pdf>. Acesso em: 01 dez. 2012.

INTERNATIONAL LABOUR OFFICE. Labour Inspection Report III (Part 1B). International Labour Conference, 95th Session, 2006. Disponível em: <http://www.ilo.org/public/english/standards/relm/ilc/ ilc95/pdf/rep-iii-1b.pdf>. Acesso em: 15 dez. 2012.

MIRANDA, C. R.; DIAS, C. R. PPRA/PCMSO: auditoria, inspeção do trabalho e controle social. Cadernos de Saúde Pública, Rio de Janeiro, v. 20, n. 1, p. 224-232, fev. 2004.

PIRES, R. R. C. Estilos de implementação e resultados de políticas públicas: fiscais do Trabalho e o cumprimento da lei trabalhista no Brasil. DADOS Revista de Ciências Sociais, Rio de Janeiro, vol 52, n. 3, p. 735-769, 2009.

SANTOS, L.; RESCHKE, L. M.; MONTEIRO, A. L. SUS: competência nas ações de Saúde do Trabalhador. [S.I.: s.n.], 1996. Parecer apresentado à Comissão Intersetorial de Saúde do Trabalhador (CIST) do Conselho Nacional de Saúde do Ministério da Saúde.

UNITED STATES OF AMERICA. Department of Labor. Bureau of Labor Statistics. National Census of fatal Occupational Injuries in 2009 (Preliminary results). 2010. Disponível em: < http://www.bls.gov/news. release/archives/cfoi_08192010.pdf > . Acesso em: 11 jun. 2012.

WEIL, D. Un planteamiento estratégico de la inspección del trabajo. Revista Internacional del Trabajo, v. 127, n. 4, p. 389-419, 2008. Disponível em: <http://www.ilo.org/public/spanish/revue/download/ pdf/s3_weil.pdf>. Acesso em: 15 jun. 2014. 